\title{
Calcium dysregulation via L-type voltage- dependent calcium channels and ryanodine receptors underlies memory deficits and synaptic dysfunction during chronic neuroinflammation
}

\author{
Sarah C Hopp ${ }^{1}$, Heather M D'Angelo ${ }^{2}$, Sarah E Royer ${ }^{1}$, Roxanne M Kaercher ${ }^{2}$, Alexis M Crockett ${ }^{1,2}$, \\ Linda Adzovic ${ }^{2}$ and Gary L Wenk $k^{1,2^{*}}$
}

\begin{abstract}
Background: Chronic neuroinflammation and calcium $\left(\mathrm{Ca}^{+2}\right)$ dysregulation are both components of Alzheimer's disease. Prolonged neuroinflammation produces elevation of pro-inflammatory cytokines and reactive oxygen species which can alter neuronal $\mathrm{Ca}^{+2}$ homeostasis via L-type voltage-dependent $\mathrm{Ca}^{+2}$ channels (L-VDCCS) and ryanodine receptors (RyRs). Chronic neuroinflammation also leads to deficits in spatial memory, which may be related to $\mathrm{Ca}^{+2}$ dysregulation.

Methods: The studies herein use an in vivo model of chronic neuroinflammation: rats were infused intraventricularly with a continuous small dose of lipopolysaccharide (LPS) or artificial cerebrospinal fluid (aCSF) for 28 days. The rats were treated with the L-VDCC antagonist nimodipine or the RyR antagonist dantrolene.

Results: LPS-infused rats had significant memory deficits in the Morris water maze, and this deficit was ameliorated by treatment with nimodipine. Synaptosomes from LPS-infused rats had increased $\mathrm{Ca}^{+2}$ uptake, which was reduced by a blockade of L-VDCCs either in vivo or ex vivo.
\end{abstract}

Conclusions: Taken together, these data indicate that $\mathrm{Ca}^{+2}$ dysregulation during chronic neuroinflammation is partially dependent on increases in L-VDCC function. However, blockade of the RyRs also slightly improved spatial memory of the LPS-infused rats, demonstrating that other $\mathrm{Ca}^{+2}$ channels are dysregulated during chronic neuroinflammation. $\mathrm{Ca}^{+2}$-dependent immediate early gene expression was reduced in LPS-infused rats treated with dantrolene or nimodipine, indicating normalized synaptic function that may underlie improvements in spatial memory. Pro-inflammatory markers are also reduced in LPS-infused rats treated with either drug. Overall, these data suggest that $\mathrm{Ca}^{+2}$ dysregulation via L-VDCCS and RyRs play a crucial role in memory deficits resulting from chronic neuroinflammation.

Keywords: Calcium, Neuroinflammation, Ryanodine receptors, L-type voltage-dependent calcium channels, Spatial memory

\section{Introduction}

Chronic neuroinflammation is a component of normal aging and may contribute to age-related cognitive decline as well as neurodegenerative disorders such as Alzheimer's disease (AD; [1]). One of the primary effector cells of neuroinflammation are microglia, the resident macrophages of the central nervous system. Normally, microglia contribute

\footnotetext{
* Correspondence: wenk.6@osu.edu

'Departments of Neuroscience, Ohio State University, Columbus, OH 43210, USA ${ }^{2}$ Department of Psychology, Ohio State University, 1835 Neil Ave, Columbus, $\mathrm{OH} 43210$, USA
}

to normal neuronal function, but chronic microglia activation can cause damage to nearby neurons [2]. Several aspects of $\mathrm{AD}$ can be replicated by chronic infusion of lipopolysaccharide (LPS) into the fourth ventricle of young rats $([3,4]$. Chronic neuroinflammation in young rats impairs performance in a variety of memory tasks [5] and such memory impairments are associated with long-term potentiation (LTP) deficits [6].

$\mathrm{Ca}^{+2}$ handling is altered in non-neuronal tissues derived from $\mathrm{AD}$ patients and family members [7]. Epidemiological studies have shown that the use of L-type voltage-dependent 
calcium channel (L-VDCC) antagonists by patients with cardiovascular conditions is associated with a reduced incidence of $\mathrm{AD}$ in [8] and patients treated with the L-VDCC antagonist nimodipine have improved cognitive scores compared to placebo-treated patients [9]. Ryanodine receptors (RyRs) may represent a novel target for treatment of Alzheimer's disease. RyR expression is altered in patients with $\mathrm{AD}$ and mild cognitive impairment [10], and patients with sporadic $\mathrm{AD}$ both have L-VDCC and RyR mutations that interact to increase and have amyloid deposition [11], demonstrating the importance of these two channels in the AD pathology. In addition to normalizing calcium dysregulation, targeting of RyRs and L-VDCCs in vitro is anti-inflammatory [12-14], and previous epidemiological studies have revealed that use of other anti-inflammatory drugs such as nonsteroid anti-inflammatory drugs (NSAIDs) also reduces Alzheimer's disease incidence [15].

Neuroinflammation and neuronal $\mathrm{Ca}^{+2}$ dysregulation may interact, synergistically leading to memory deficits. Neuroinflammation increases glutamatergic activity by suppression of glutamate transport ([13,16-18]) while potentiating activity of $\mathrm{N}$-methyl $\mathrm{D}$-aspartate receptors (NMDARs; [19-21]). Similarly, pro-inflammatory cytokines and nitric oxide $(\mathrm{NO})$ can increase the function of L-VDCCs [22] and RyRs [23,24]. Both NMDARdependent and L-VDCC-dependent LTP are disrupted during chronic neuroinflammation [25]. Additionally, the function of RyRs and L-VDCCs are linked not only to each other but also to the function of NMDARs [26-28]. RyRs interact with NMDARs by amplifying NMDAR $\mathrm{Ca}^{+2}$ signals [26], while L-VDCCs can decrement relevant NMDAR event-related signaling by lengthening the after hyperpolarization [28]. Overall, these data suggest that these channels can all act synergistically to increase intracellular $\mathrm{Ca}^{+2}$ concentration during neuroinflammation and disrupt normal processes that underlie memory. Increased intracellular $\mathrm{Ca}^{+2}$ could lead to memory deficits via dysregulated activation of $\mathrm{Ca}^{+2}$-dependent kinases and subsequent production of immediate early genes (IEGs) such as activity-regulated cytoskeletonassociated protein $(A r c)$.

Overall, these data have led to the following hypotheses. 1) If neuroinflammation leads to increases in intracellular $\mathrm{Ca}^{+2}$ levels, then increased Arc production should be observed in tissue from rats chronically infused with LPS, since Arc induction is $\mathrm{Ca}^{+2}$ dependent [29]. Furthermore, transport of $\mathrm{Ca}^{+2}$ should be observed directly in synaptosomes generated from the hippocampus of these rats. 2) If neuroinflammation-induced memory deficits are due to increased intracellular $\mathrm{Ca}^{+2}$ and dysregulation of L-VDCCs and/or RyRs, then pharmacological blockade of these channels should improve spatial memory deficits and normalize $\mathrm{Ca}^{+2}$ levels and activity of $\mathrm{Ca}^{+2}$-dependent markers.

\section{Methods}

\section{Subjects and surgical procedures}

The subjects were male F-344 (Harlan, Indianapolis, IN, USA) rats, 3 months old, individually housed with ad libitum access to food and water and maintained on a reverse 12/12 light/dark cycle with lights off at $8 \mathrm{AM}$. Artificial cerebrospinal fluid (aCSF, $140 \mathrm{mM} \mathrm{NaCl}, 3.0 \mathrm{mM}$ $\mathrm{KCl}, 2.5 \mathrm{mM} \mathrm{CaCl} 2,1.0 \mathrm{mM} \mathrm{MgCl} 2,1.2 \mathrm{mM} \mathrm{Na} 2 \mathrm{HPO} 4$, $\mathrm{pH} 7.4 ; n=40$ ) or LPS (Sigma, St. Louis, MO, USA, Escherichia coli serotype 055:B5 TCA extraction, $1.0 \mathrm{mg} / \mathrm{ml}$ dissolved in aCSF, $n=43$ ) was loaded into an osmotic minipump (Alzet model \#2004, with a rate of $0.25 \mu \mathrm{l} / \mathrm{hr}$, Durect Corp., Cupertino, CA, USA) and infused into the brain for 28 days via a cannula surgically implanted into the fourth ventricle as previously described [30]. The day after the osmotic minipump was implanted, rats began to receive daily subcutaneous drug injections at a volume of $1 \mathrm{ml} / \mathrm{kg}$ per day with a vehicle (polyethylene glycol 300, Thermo Fisher Scientific, Waltham, MA, USA), dantrolene sodium salt $(5 \mathrm{mg} / \mathrm{kg} /$ day, Sigma), or nimodipine $(5 \mathrm{mg} / \mathrm{kg} /$ day, Sigma), resulting in six group + drug treatment groups (aCSF + vehicle, $n=14$; aCSF + dantrolene, $n=13$; aCSF + nimodipine, $n=13$; LPS + vehicle, $n=16$; LPS + dantrolene, $n=14$; LPS + nimodipine, $n=14$ ). Body weights were monitored daily, and rats were given saline injections and supplemental food postoperatively to prevent dehydration and weight loss. This research was carried out in accordance with the National Institutes of Health Guide for the Care and Use of Laboratory Animals (NIH Publication No. 80-23) and The Ohio State University Institutional Animal Care and Use Committee.

\section{Behavioral testing}

The rats were handled daily for 1 week prior to surgery and daily up until behavioral testing, which took place on the third week following surgery. Spatial learning was assessed in the Morris water maze (MWM), using a $170-\mathrm{cm}$ diameter pool with gray walls surrounded by multiple visual distal and proximal cues. The water was maintained at room temperature $\left(\mathrm{RT} ; 21^{\circ} \mathrm{C}\right.$ to $22^{\circ} \mathrm{C}$ ). During the hidden platform portion of the task, a circular escape platform was present in a consistent location and submerged $2.5 \mathrm{~cm}$ below the water surface. The rats were tracked using overhead cameras and Noldus Ethovision 3.1 tracking and analysis stem (Noldus, Lessburg, VA, USA). On the first day, rats were placed on the hidden platform for $30 \mathrm{~s}$ prior to the trial. Each rat performed six trials per day separated by a 60 -min inter-trial interval for four consecutive days. The rat was released into the water at one of six randomized locations which were varied such that rats were could not take the same path to the hidden platform more than once per day. After the rat located the hidden platform or swam for a maximum of $60 \mathrm{~s}$, it was placed on the platform for $30 \mathrm{~s}$. After the last training trial 
on the fourth day, the rats were tested in a 60-s probe trial where the platform was removed from the pool. Finally, at the end of the fourth day, the rats were tested in a visual platform test where the platform was moved to a new quadrant and raised $2 \mathrm{~cm}$ above the surface of the water in order to control for any group- or drug-related differences in visual acuity or swimming ability. All rats across all groups were able to locate the visible platform. Three days after the conclusion of the water maze task, in order to assess expression of the behaviorally induced immediate early gene $A r c$, rats were exposed to a novel context 30 min prior to sacrifice. The novel context was an exploration box $(36 \times 48 \mathrm{~cm})$ surrounded by proximal and distal visual stimuli.

\section{Tissue collection}

All of the rats were deeply anesthetized using isoflurane prior to sacrifice. One cohort of rats was used for histology ( $n=6$ per each group + drug) and another used for biochemistry ( $n=7$ to 10 per each group + drug). The histology cohort underwent transcardiac perfusion with cold saline containing $1 \mathrm{U} / \mathrm{ml}$ heparin followed by 4\% paraformaldehyde in $0.1 \mathrm{M}$ phosphate buffer, $\mathrm{pH}$ 7.4. The brains were post-fixed overnight in fixative and then stored at $4^{\circ} \mathrm{C}$ in phosphate-buffered saline (PBS), pH 7.4. The biochemistry cohort was rapidly decapitated and their hippocampi dissected on ice and separated such that the right or left sides were randomly chosen for either protein or gene expression analysis. The hippocampi were stored at $-80^{\circ} \mathrm{C}$ until RNA or protein extraction. A separate cohort of rats was used for ${ }^{3} \mathrm{H}$-radioligand binding assays, cell isolation procedures, and generation of synaptosomes for use in the ${ }^{45} \mathrm{Ca}^{+2}$ uptake ( $n=10$ /group). For these rats, one hippocampus was used immediately for the generation of synaptosomes.

\section{Immunohistochemistry}

Free-floating coronal sections $(40-\mu \mathrm{m}$ thickness) were generated using a vibratome and stained using standard avidin/biotin-peroxidase-labeling methods as previously described [31]. The rabbit polyclonal antibody against $\operatorname{Arc}$ (final dilution 1:2,000; Synaptic Systems, Goettingen, Germany) was used to label behaviorally activated neurons; the mouse monoclonal antibody against OX-6 (final dilution 1:200; BD Pharmigen, San Diego, CA, USA) was used to label major histocompatibility complex II (MHC-II) on activated microglia; and the mouse monoclonal antibody against glial fibrillary acid protein (GFAP; final dilution 1:2,000; Millipore Chemicon, Billerica, MA, USA) was used to quantify astrocyte activation. Briefly, endogenous peroxidase activity was quenched and nonspecific binding was blocked with $5 \%$ normal goat serum (NGS) in PBS (OX-6 and GFAP) or Tris-buffered saline (TBS) with 5\% Tween $(A r c)$. Sections were then incubated overnight at $4^{\circ} \mathrm{C}$ in primary antibody diluted in the same blocking solution. The next day, sections were rinsed and then incubated for $1.5 \mathrm{~h}$ at RT in biotinylated secondary antibody from the appropriate species (final dilution 1:200, Vector, Burlingame, CA, USA). Sections were then rinsed and incubated for $1 \mathrm{~h}$ at $\mathrm{RT}$ with avidin-biotinylated horseradish peroxidase (Vectastain, $A B C$ kit, Vector). After another rinse, sections were incubated with $0.05 \%$ 3, 3'-diaminobenzidine tetrahydrochloride (Vector) as a chromogen. The reaction was stopped by rinsing the sections with PBS. No staining was detected in the absence of primary or secondary antibodies. Sections were mounted on superfrost slides, air-dried, dehydrated with a series of ethanol and xylene rinses, and cover slipped with cytoseal (Allan Scientific, Kalamazoo, MI, USA) mounting medium. Images of the hippocampi were captured with light microscopy, stitched together, and analyzed with a Nikon 90i system with a DS-5 M-L1 digital camera using Elements 3.1 Software (Nikon Instruments, Melville, NY, USA). Subfields of interested were determined as previously reported [32]. OX-6 was quantified using automated cell-counting methods as previously described [6]. OX-6 immunoreactive objects larger than $65 \mathrm{~mm}^{2}$ were included in analysis, and data are expressed as number of objects per $\mathrm{mm}^{2}$. Arc and GFAP were quantified using intensity densitometry and data are expressed as \% area (of the region of interest).

RNA isolation and quantitative polymerase chain reaction Total RNA was isolated from hippocampi with phenolchloroform extraction using PureZol (Bio-Rad, Hercules, CA) followed by cleanup using NucleoSpin RNA II kits (Machery-Nagel, Düren, Germany) according to the manufacturers' instructions. RNA quantity was measured using a Synergy Plate reader equipped with a Take- 3 plate (Bio-Tek, Winooski, VT, USA) and $1 \mu \mathrm{g}$ from each sample was used to generate cDNA with iScript reverse transcription Supermix kit (Bio-Rad) using a C1000 Thermal Cycler (Bio-Rad). Selected RNA samples were run without reverse polymerase as a control to ensure no contamination from genomic DNA. Primers were designed using the PrimerQuest software (Integrated DNA Technologies, Coralville, IA, USA; Table 1). Gene expression was quantified using SsoAdvanced Universal SYBR Green (Bio-Rad) quantitative polymerase chain reaction (qPCR) on a CFX96 Real-Time PCR detection system (Bio-Rad). Glyceraldehyde3-phosphate dehydrogenase (GAPDH) was used as a reference gene. Data were analyzed using the comparative threshold cycle method with results expressed as a fold change versus aCSF + vehicle rats.

\section{${ }^{45} \mathrm{Ca}^{+2}$ synaptosomal uptake}

A ${ }^{45} \mathrm{Ca}^{+2}$ synaptosomal uptake assay was used in order to determine whether LPS treatment would increase 
Table 1 Primer sequences

\begin{tabular}{|c|c|c|c|}
\hline Target & Accession \# & Forward & Reverse \\
\hline GAPDH & NM_017008 & TGACTCTACCCACGGCAAGTTCAA & ACGACATACTCAGCACCAGCATCA \\
\hline RyR1 & AF112256 & TGCGCTCCAACCAGGATCTCATTA & TCACCTCGAAGTACCACTTGCCATAC \\
\hline RyR2 & AF112257 & GGACTTGAAGGAACTGACGGAGGAAA & CACTGAGACCAGCATTTGGGTTGTG \\
\hline RyR3 & AF130881 & TGGCCTCCTGGCTGTAGTTGTTAA & ACCTGCTCTTACGCCCACATACAT \\
\hline VDCC a1c & NM_012517 & GGCTATGAGTTGCCCTGGGTGTATTT & CGAGCTTTGGCTITCTCCCTCTCTIT \\
\hline VDCC ald & NM_017298 & TGCATGACATTGGGCCAGAAATCC & AGTTCCAAGCAGGGCACCATTTC \\
\hline$I L-1 \beta$ & NM_031512 & ACCTGCTAGTGTGTGATGTTCCCA & AGGTGGAGAGCTITCAGCTCACAT \\
\hline TNFa & X66539.1 & CTGGCCAATGGCATGGATCTCAAA & AGCCTTGTCCCTTGAAGAGAACCT \\
\hline TGF $\beta$ & NM_021578 & TGATACGCCTGAGTGGCTGTCTIT & TTGCTGTCACAAGAGCAGTGAGC \\
\hline iNOS & NM_012611 & AGTTCCAAGCAGGGCACCATTTC & TGGGTGTCAGAGTCTTGTGCCTIT \\
\hline ARC & NM_017134 & AGCTACCTGCTGGGAAGGAAGAAA & СTTCTCTGTAAGATAGGCCTCCCACAAC \\
\hline CD200 ligand & NM_031518 & CCTGAACGTGTITCCCTGGTCTACTT & GTCAAATCCCTCACAGGCTTCCTTCT \\
\hline CD200 receptor & NM_023953 & GCGGCTGAGTCAAGTTGTCCTGATA & TGAAATAGAAGGGCAGCAGAGCAGAG \\
\hline
\end{tabular}

$\mathrm{Ca}^{+2}$ uptake and whether such an observed increase could be blocked by L-VDCC antagonism. Rats infused with LPS or aCSF and treated with vehicle or nimodipine were used for this assay. Synaptosomes were generated immediately from freshly dissected hippocampus by Teflon/glass homogenization in $0.32 \mathrm{mM}$ sucrose. Homogenates were centrifuged at 3,000 RPM for $10 \mathrm{~min}$ at $4^{\circ} \mathrm{C}$, followed by a second centrifugation of the supernatant at 12,000 RPM for $10 \mathrm{~min}$ at $4^{\circ} \mathrm{C}$. The resulting pellet containing synaptosomes was then resuspended in HEPES buffer $(125 \mathrm{mM}$ $\mathrm{NaCl}, 3.5 \mathrm{mM} \mathrm{KCl}, 0.4 \mathrm{mM} \mathrm{KH} \mathrm{PO}_{4}, 1.2 \mathrm{mM} \mathrm{MgSO}_{4}$ 7(H2O), $10 \mathrm{mM}$ d-glucose, $1 \mathrm{mM} \mathrm{CaCl}_{2}$, and $20 \mathrm{mM}$ HEPES) and placed on ice until use. An aliquot of each sample was saved for protein quantification using a Bio-Rad protein assay. HEPES buffer with $0.03 \mathrm{mM}$ nimodipine (Nim-HEPES) was prepared for use during the blocked condition. HEPES buffer $(60 \mu \mathrm{l})$ containing $0.01 \mu \mathrm{Ci} / \mu \mathrm{l}$ of ${ }^{45} \mathrm{Ca}^{+2}$ (Perkin Elmer, Boston, MA, USA) was added to an incubation vial followed by $60 \mu \mathrm{l}$ of either HEPES buffer or Nim-HEPES. Synaptosomes $(60 \mu \mathrm{l})$ were added last and incubated at RT for $1 \mathrm{~min}$ and uptake was stopped by filtration onto $0.45-\mu \mathrm{m}$ nitrocellulose filters (Millipore, Billerica, MA, USA). Filters were transferred to scintillation vials and filled with scintillation fluid (Formula 989, Perkin Elmer, Boston, MA, USA). Vials were loaded into a liquid scintillation counter (1900 TR Tri Carb, Packard Instrument Company/Perkin-Elmer) and number of decays per minute (DPMs) were counted over $10 \mathrm{~min}$ per sample. All samples were run in triplicate, plus blanks and external standards containing $10 \mu \mathrm{l}$ of the HEPES buffer containing $0.01 \mu \mathrm{Ci} / \mu \mathrm{l}$ of ${ }^{45} \mathrm{Ca}^{+2}$. For data analysis, blank values were subtracted from the sample values; DPMs were converted to moles of ${ }^{45} \mathrm{Ca}^{+2}$ based on the specific activity of the radioisotope and Curie's constant. Finally, the moles of ${ }^{45} \mathrm{Ca}^{+2}$ were divided by protein content of $60 \mu \mathrm{l}$ of synaptosomes such that data are presented as moles of ${ }^{45} \mathrm{Ca}^{+2}$ per mg protein.

\section{Statistical analyses}

Statistical analyses were conducted using SigmaPlot 12.5 (Systat, San Jose, CA, USA). Analyses of variance (ANOVA) were performed followed by either the Bonferroni correction to counteract the problem of multiple post hoc comparisons associated with analysis of the MWM data or Fisher's protected least significant difference for post hoc comparisons for the biochemistry and histology data. Graphs display the mean plus standard error of the mean (SEM). A $P<0.05$ was considered statistically significant.

\section{Results}

Blockade of L-VDCCs or RyRs improves spatial memory during chronic neuroinflammation

After 3 weeks of LPS or aCSF infusion and treatment with vehicle, dantrolene, or nimodipine ( $n=12$ to 15 /group), we tested the rats' performance in the MWM (Figure 1). We examined the path length that rats took to locate the hidden platform (Figure 1A), with longer path lengths indicative of a spatial learning deficit. We first performed a three-way ANOVA (infusion group $\times$ drug group $\times$ day of testing) and then a post hoc two-way repeated measures (RM)-ANOVA (combining infusion group and drug group $\times$ day of testing) as described previously when using a similarly designed study [33]. The three-way ANOVA revealed significant memory deficits due to LPS $(F(1,296)=47.057, P<0.001)$ and improvements related to drug treatment $(F(2,296)=5.050, P=0.007)$ and day $(F(3,296)=45.838, P<0.001)$. A post hoc two-way RM-ANOVA revealed significant main effects due to the 


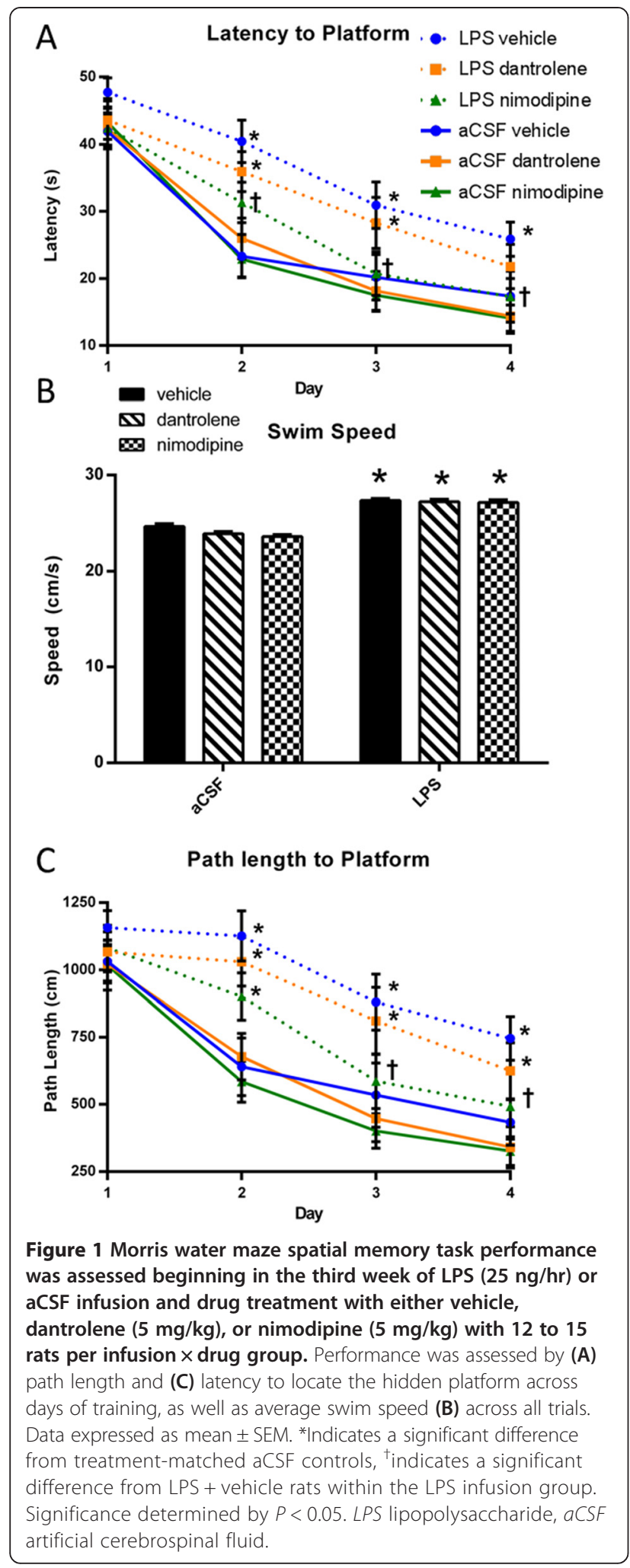

infusion + drug group $(F(5,222)=5.150, P<0.001)$ and improvements related to day $(F(3,222)=86.911, P<0.001)$. LPS + vehicle rats were significantly impaired compared to
aCSF + vehicle rats on days 2 to $4(P<0.05)$. Nimodipine treatment reversed LPS-induced deficits on days 3 and 4; specifically, LPS + nimodipine-treated rats took significantly $(P<0.05)$ shorter paths than LPS + vehicle rats and took paths that were not significantly $(P>0.150)$ different than their aCSF controls on days 3 and 4. Dantrolene treatment did not improve LPS-induced deficits, as LPS + dantrolene rats took significantly longer paths than their controls on all the days of testing $(P<0.05)$ and were not significantly different from the LPS + vehicle rats $(P>0.05)$. We found that LPS-treated rats had significantly faster swim speeds (Figure $1 B ; F(1,74)=29.173$, $P<0.001)$ and post hoc analysis showed that every LPS group swam faster than their respective aCSF control $(P<0.01)$. Despite their increased swimming speed, LPSinfused rats also took more time to locate the hidden platform $(F(1,296)=33.340, P<0.001)$, as measured by latency to locate the hidden platform. Significant improvements in latency were observed related to drug treatment $(F(2,296)=5.043, P=0.007)$ and day of testing $(F(3,296)=$ $80.392, P<0.001)$. Similar to the results obtained with distance taken to locate the hidden platform (Figure 1C). A post hoc two-way RM-ANOVA revealed that the LPS + vehicle rats took significantly $(P<0.05)$ more time than the aCSF + vehicle rats to locate the hidden platform on days 2 to 4 . Nimodipine treatment completely reversed LPS-induced deficits; specifically, the LPS + nimodipinetreated rats took significantly $(P<0.05)$ less time than the LPS + vehicle rats and were not significantly different $(P>0.05)$ from their aCSF controls on days 2 to 4 . Dantrolene treatment led to a partial recovery of the LPSinduced deficit; specifically, the LPS + dantrolene-treated rats were not significantly different $(P>0.07)$ from their aCSF controls on day 4. There was no difference between any of the groups on day $1(P>0.05)$, suggesting that baseline performance was not driving the performance differences observed on the subsequent days of testing. There was also no difference between the aCSF groups on any day $(P>0.05)$, indicating that neither dantrolene nor nimodipine have cognitive enhancing effects or side effects that are detrimental to learning. For the probe trial, a two-way ANOVA revealed a significant main effect of infusion group $(F(1,76)=4.093, P=0.047)$. Overall, poor performance in the MWM was correlated with expression of the CaV1.2 subunit of the L-VDCC $(P<0.05$ by Pearson correlation). Overall, these data indicate that LPS-induced spatial memory deficits in the MWM can be reversed by blockade of L-VDCCs, while blockade of RyRs only confers a minor improvement.

\section{Blockade of L-VDCCs or RyRs during chronic neuroinflammation reduces aberrant expression of Arc}

Due to the spatial memory improvements we observed in LPS-infused rats treated with drugs that normalize or 
reduce intracellular $\mathrm{Ca}^{+2}$ concentration, we examined levels of the IEG Arc, which is $\mathrm{Ca}^{+2}$ dependent. We examined expression of Arc protein in brains perfused $30 \mathrm{~min}$ after exposure to a novel spatial environment and found region-specific changes in levels as measured by immunohistochemistry and densitometry (Figure 2A, B). A two-way ANOVA revealed that Arc expression in the CA3 subfield of the hippocampus was increased by LPS infusion $(F(1,129)=14.614, P<0.001)$ and trended toward a main effect in the dentate gyrus (DG) subfield $(F(1,129)=3.712, P=0.056)$, with a significant LPS and drug interaction in the DG $(F(2,129)=3.576, P=0.031)$. In the DG, treatment with dantrolene or nimodipine reduced LPS-induced overexpression of $\operatorname{Arc}(P=0.001$ and $P=0.002$, respectively) to aCSF levels. In the CA3, dantrolene treatment led to a slight reduction in LPSinduced $A r c$ overexpression, and nimodipine treatment significantly reduced $A r c$ overexpression. In the CA1, significant changes in Arc were related to drug treatment $(F(1,129)=5.043, P=0.007)$. The CA1 of vehicle-treated LPS-infused rats showed a trending increase in Arc $(P=0.079)$ compared to aCSF controls, which was significantly reduced by treatment with dantrolene or nimodipine ( $P=0.050$ and $P=0.027$, respectively). Overall, chronic neuroinflammation increased expression of $A r c$ and reduction of intracellular $\mathrm{Ca}^{+2}$ via $\mathrm{L}-\mathrm{VDCC}$ or $\mathrm{RyR}$ blockade reduced these increases.

\section{$\mathrm{Ca}^{+2}$ dysregulation during chronic neuroinflammation is dependent on L-VDCC activity}

We hypothesized that chronic LPS infusion was triggering $\mathrm{Ca}^{+2}$ dysregulation, since we found that LPS infusion increases the $\mathrm{Ca}^{+2}$-dependent immediate early gene Arc and that increase is blocked by $\mathrm{Ca}^{+2}$ channel blockers. $\mathrm{Ca}^{+2}$ dysregulation in aging and $\mathrm{AD}$ has been associated with increases in L-VDCCs or RyRs [10,34-36]. Here, we examined hippocampal gene expression levels of the L-VDCC subunits a1c (CaV1.2) and a1d (CaV1.3), both of which are pharmacologically blocked by nimodipine, and found no significant differences $(P>0.05)$ across any LPS or drug treatments (Figure 3A, B). We also examined gene expression of the three RyR isoforms and found no significant differences $(P>0.05)$ across any LPS or drug treatments (Figure $3 \mathrm{C}, \mathrm{D}, \mathrm{E}$ ).

We tested whether chronic neuroinflammation would functionally increase intracellular $\mathrm{Ca}^{+2}$ uptake by generating synaptosomes from fresh hippocampus from rats infused with chronic LPS or aCSF and treated with vehicle or nimodipine and measuring ${ }^{45} \mathrm{Ca}^{+2}$ uptake using liquid scintillation (Figure 4). At baseline (Figure 4A),

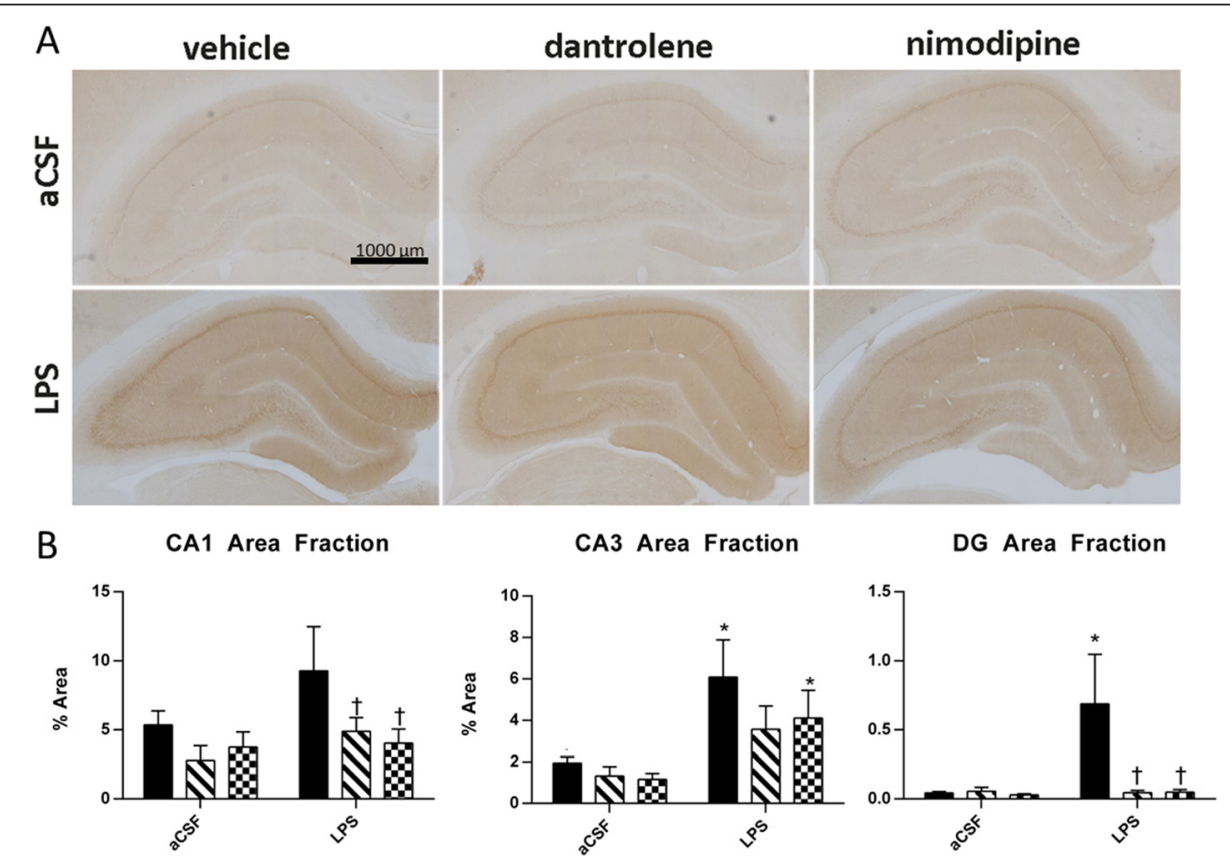

Figure 2 Hippocampal immunohistochemistry against Arc was quantified across in brains perfused $\mathbf{3 0}$ min after rats were exposed to a novel context. (A) Representative slices of hippocampal Arc immunohistochemistry after 4 weeks of infusion with aCSF (top row) or LPS (bottom row) and treatment with vehicle (first column), dantrolene (middle column), or nimodipine (third column). (B) Quantification of Arc immunostaining in CA1, CA1, and DG. Data expressed as mean \pm SEM. *Indicates a significant difference from treatment-matched aCSF controls, ${ }^{\dagger}$ indicates a significant difference from LPS + vehicle rats within the LPS group. Significance determined by $P<0.05$. LPS lipopolysaccharide, aCSF artificial cerebrospinal fluid, DG dentate gyrus. 

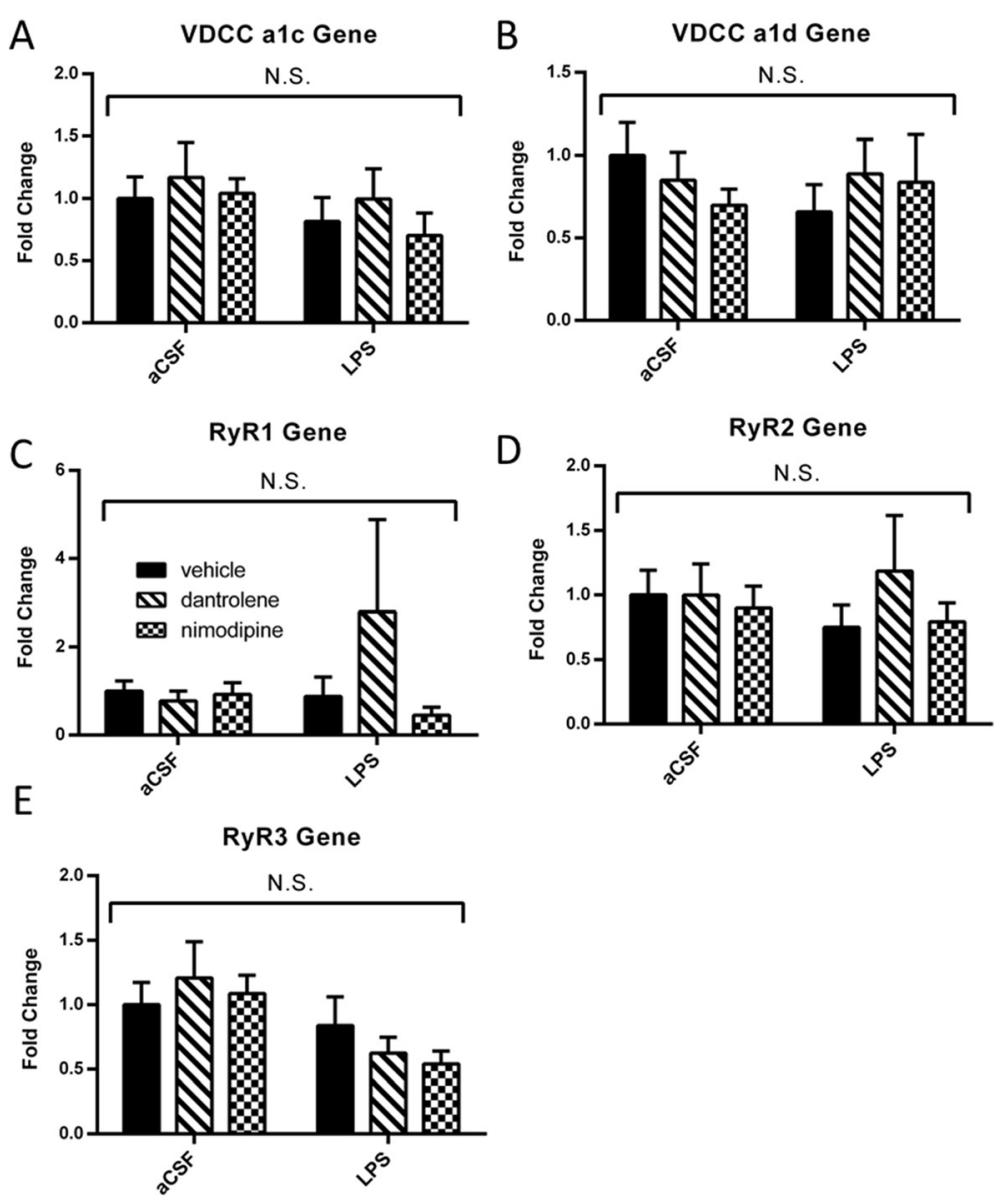

Figure 3 Chronic LPS infusion did not change gene expression of either L-VDCC subunits or any of the RyR isoforms (A, B, C, D, E). Data expressed as mean \pm SEM. N.S. indicates no significant differences. Significance determined by $P<0.05$. LPS lipopolysaccharide, aCSF artificial cerebrospinal fluid, VDCC voltage-dependent $\mathrm{Ca}^{+2}$ channel, $R y R$ ryanodine receptor.

a two-way ANOVA revealed a significant main effect of drug $(F(1,34)=4.410, P=0.043)$ and a trend toward a group main effect $(F(1,34)=3.169, P=0.084)$. Post hoc analyses revealed that the LPS + vehicle rats had significantly more moles of ${ }^{45} \mathrm{Ca}^{+2}$ uptake per mg of protein compared to the aCSF + vehicle rats $(P=0.034)$ as well as compared to the LPS + nimodipine rats $(P=0.026)$. The LPS + nimodipine rats were no different from the aCSF + nimodipine rats or aCSF + vehicle rats $(P>0.5)$. These results demonstrated that increases in $\mathrm{Ca}^{+2}$ were dependent on L-VDCC activity, since nimodipine was able to reverse LPS-associated increases in $\mathrm{Ca}^{+2}$ uptake. In order to elucidate the role of L-VDCCs, we applied $10 \mu \mathrm{M}$ of nimodipine ex vivo to the same hippocampal synaptosomal preparations (Figure 4B). With ex vivo nimodipine, there were no differences across any LPS or drug treatments $(P>0.2)$. When we examined the data with a three-way ANOVA across the two conditions (baseline and blocked, Figure 4C), we found a significant main effect of group $(F(1,67)=4.73, P=0.033)$ and $\operatorname{drug}(F(1,67)=5.794$, $P=0.019)$, but not between conditions $(F(1,67)=0.655$,
$P=0.421)$. Overall, these data demonstrate that there is $\mathrm{Ca}^{+2}$ dysregulation during neuroinflammation that is dependent on activity of L-VDCCs.

\section{L-VDCC or RyR antagonism reduces hippocampal neuroinflammatory markers during chronic neuroinflammation}

We evaluated the role of L-VDCC and RyR antagonism on LPS-induced microglia activation in the hippocampus by performing immunohistochemistry against MHC-II (Figure 5A). Numerous activated microglia were present throughout the hippocampi of LPS-infused rats, with few present in aCSF-infused rats. MHC-II positive (MHC-II+) cells were counted in specific hippocampal subfields (Figure 5B, C, D). Very few activated microglia were present in the CA1 subfield (Figure 5A), with no differences across any of the groups $(P>0.3)$. The CA3 and DG (Figure 5C, D) subfields had more MHC-II+ cells, and two-way ANOVAs revealed a significant main effect of drug and group in the CA3 $(F(2,122)=3.069, P=0.050$ and $F(1,122)=33.642, P<0.001$, respectively) and a 


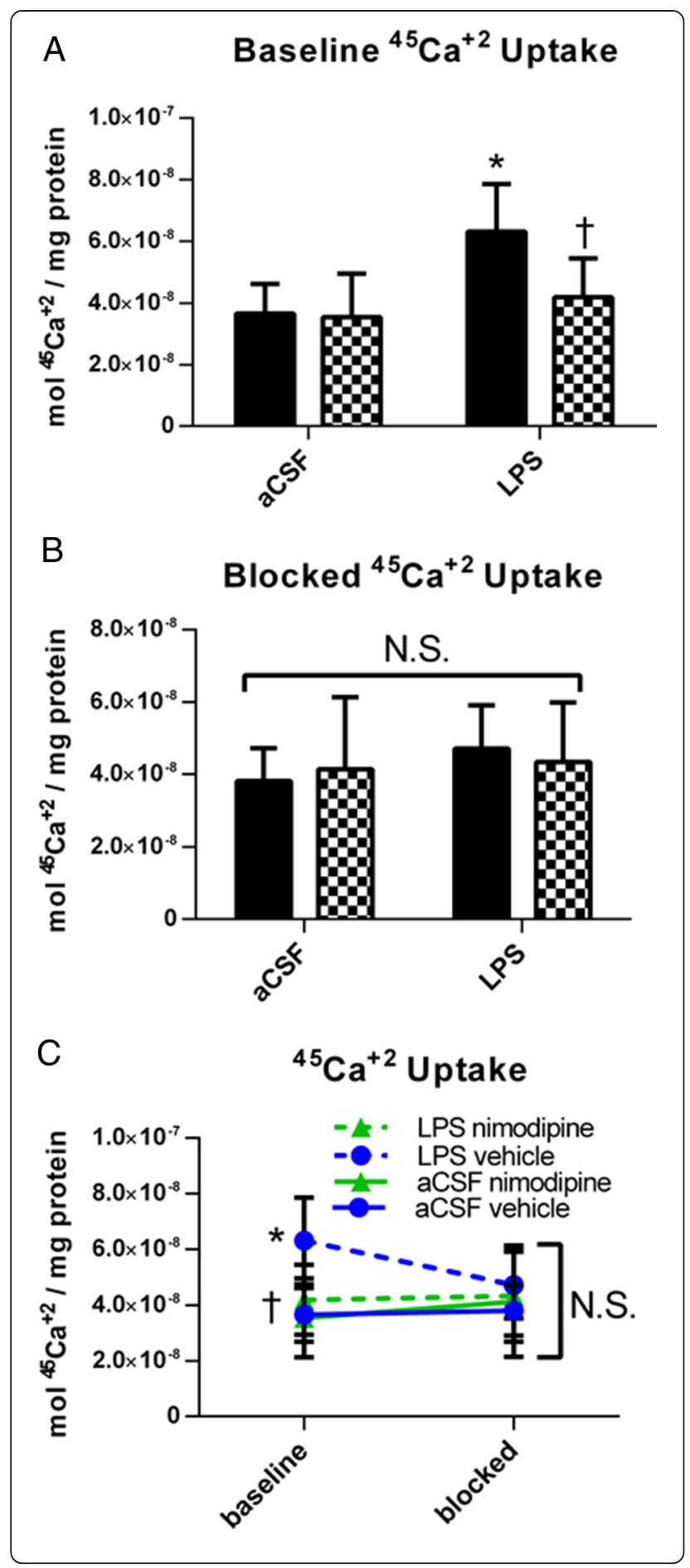

Figure 4 Chronic LPS infusion increased hippocampal synaptosomal uptake of ${ }^{45} \mathrm{Ca}^{+2}$ and this increase was reduced by treatment with nimodipine in vivo ( $A$ ) or ex vivo (B and $C$ ). (A) Baseline ${ }^{45} \mathrm{Ca}^{+2}$ uptake by hippocampal synaptosomes isolated from rats infused with LPS or aCSF for 4 weeks and treated with vehicle or nimodipine. (B) ${ }^{45} \mathrm{Ca}^{+2}$ uptake by hippocampal synaptosomes isolated from rats infused with LPS or aCSF for 4 weeks and treated with vehicle or nimodipine and additionally treated with ex vivo application of $30 \mu \mathrm{M}$ nimodipine. (C) Data from figures (A) and (B) for comparison of baseline uptake and blocked uptake of ${ }^{45} \mathrm{Ca}^{+2}$ with ex vivo nimodipine. Data expressed as mean \pm SEM. *Indicates a significant difference from treatment-matched aCSF controls, ${ }^{\dagger}$ Indicates a significant difference from LPS + vehicle rats, N.S. indicates no significant differences. Significance determined by $P<0.05$. LPS lipopolysaccharide, aCSF artificial cerebrospinal fluid.

significant main effect of group in the DG $(F(2,122)=$ 91.203, $P<0.001)$. Post hoc analyses on the CA3 and DG showed that LPS-infused rats treated with vehicle, dantrolene, or nimodipine all had significantly more MHC-II positive cells compared to their aCSF controls $(P<0.02)$. In the CA3, dantrolene- and nimodipinetreated LPS rats had significantly fewer MHC-II+ cells compared to vehicle-treated LPS rats $(P<0.001$ and $P=0.011$, respectively). In the DG, the LPS + dantrolene rats had fewer MHC-II+ cells than the LPS + vehicle rats $(P=0.028)$, but the LPS + nimodipine rats were not significantly different $(P>0.1)$. Overall, the blockade of RyRs and L-VDCCs reduces hippocampal microglia activation induced by chronic LPS infusion. Furthermore, changes in multiple biomarkers in response to drug treatment were likely more robust in the dentate and CA3 regions of the hippocampus, as compared to the CA1 region, due to the fact that these regions typically demonstrate a more robust inflammatory response to chronic LPS infusion [6].

We then assessed astrocyte activation after chronic LPS infusion by examining hippocampal GFAP gene expression (Figure 5E) and quantified GFAP immunohistochemistry in hippocampal subfields (Figure 5F, G, H). A two-way ANOVA revealed a trend toward interaction between drug and group $(P=0.057)$ on hippocampal GFAP gene expression, but there were no significant differences between any of the groups. Similarly, immunohistochemistry quantification revealed no significant differences in the CA1 (Figure 5F), CA3 (Figure 5G), or DG (Figure $5 \mathrm{H}$ ), although there was a trend toward significant interaction of drug and group on DG GFAP expression $(P=0.082)$. Taken together with the MHC-II immunohistochemistry data, these data demonstrate a more significant role for microglia than astrocytes in LPSinduced neuroinflammation.

We further elucidated the neuroinflammatory milieu of the hippocampus following chronic LPS infusion by evaluating several inflammatory genes in whole hippocampal homogenate (Figure 6). Two-way ANOVA revealed that 


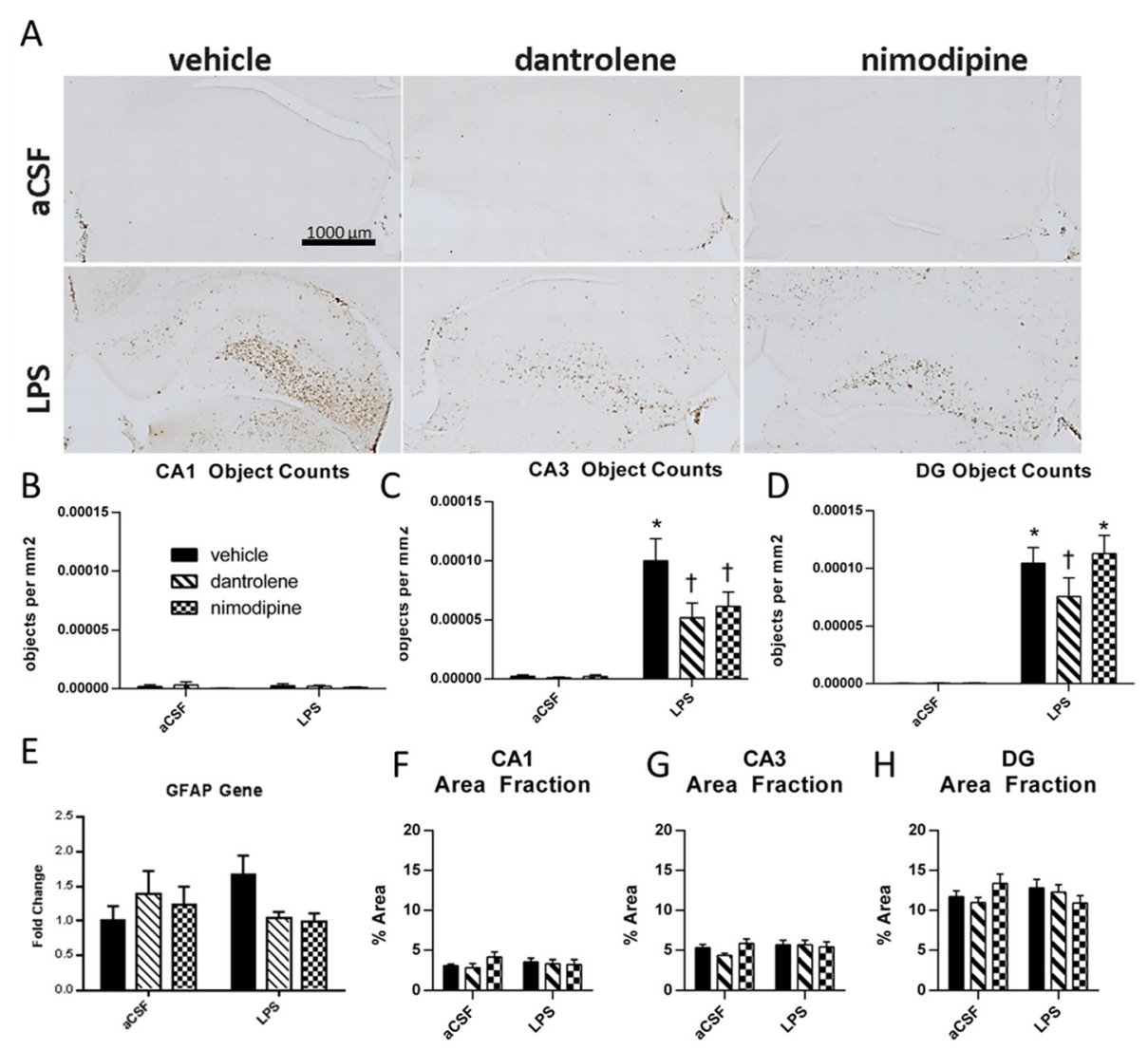

Figure 5 Chronic LPS infusion increased activation of microglia but not astrocytes, and treatment with either dantrolene or nimodipine reduced microglia activation. Activated microglia were quantified by counting $\mathrm{MHC}-\|+$ cells, and activated astrocytes were quantified by densitometry of GFAP. Hippocampal immunohistochemistry against MHC-II/OX-6 (A) and GFAP was quantified (B, C, D, F, G, H) across specific hippocampal subfields. Although the DG region in LPS-infused rats contains numerous immunoreactive objects, only those OX-6 immunoreactive objects larger than $65 \mathrm{~mm}^{2}$ were included in analysis and are represented in the histograms. GFAP hippocampal gene expression (E) was also quantified. (B) There was no change in the number of MHC-II+ cells in the CA1 subfield of the hippocampus. (C, D) There were significantly more MHC-II positive cells in the CA3 (C) and DG (D) subfield of all LPS-treated groups compared to their aCSF controls. Dantrolene treatment significantly reduced the number of $\mathrm{MHC}-11+$ cells present in the CA3 and DG subfields, and nimodipine treatment significantly reduced the number of MHC-II+ cells present in the CA3. (E) There was a trend toward a drug $\times$ group interaction for hippocampal GFAP gene expression, but no statistically significant changes were observed. $(F, G, H)$ There were no significant changes in the amount of GFAP in any of the hippocampal subfields due to either LPS or drug treatment. Data expressed as mean \pm SEM. ${ }^{*}$ Indicates a significant difference from treatment-matched aCSF controls, ${ }^{\dagger}$ Indicates a significant difference from LPS + vehicle rats. Significance determined by $P<0.05$. LPS lipopolysaccharide, aCSF artificial cerebrospinal fluid, DG dentate gyrus, GFAP glial fibrillary acid protein.

IL-1 $\beta$ and Toll-like receptor 2 and 4 (TLR2 and TLR4) gene expression was significantly affected by the LPS vs. aCSF group $(F(1,40)>4, P<0.05)$, and TLR4, inducible nitric oxide synthase (iNOS), and transforming growth factor $\beta$ (TGF $\beta$ ) gene expression was significantly affected by an interaction between drug and group $(F(2,40)>3.5$, $P<0.05)$. Post hoc analyses revealed that the LPS + vehicle rats had significant $(P<0.05)$ increases in gene expression of IL-1 $\beta$, TLR4, iNOS, TLR2, and TGF $\beta$ compared to the aCSF + vehicle rats. Treatment with nimodipine decreased the gene expression of IL-1 $\beta$, TLR4, iNOS, and TGF $\beta$ $(P=0.053$ trend, $P=0.039, P=0.085$ trend, and $P=0.033$, respectively), while treatment with dantrolene decreased gene expression of TLR4, iNOS, and TGF $\beta(P=0.007$, $P=0.050$, and $P=0.006$, respectively). For IL- $1 \beta$, iNOS, and TLR2 expression, dantrolene or nimodipine-treated LPS rats that did not reach $P<0.05$ were not significantly different than their aCSF controls or LPS + vehicle rats, indicating an intermediate reduction with drug treatment.

\section{Discussion}

Nimodipine and dantrolene differentially improved memory deficits associated with LPS infusion

Nimodipine treatment resulted in a complete recovery of spatial memory deficits induced by chronic LPS infusion as measured by performance in the MWM. These data implicate an important role of $\mathrm{Ca}^{+2}$ overloads in neuroinflammation-induced memory deficits. The mechanism by which nimodipine improves spatial memory may be by reduction of the slow after hyperpolarization 


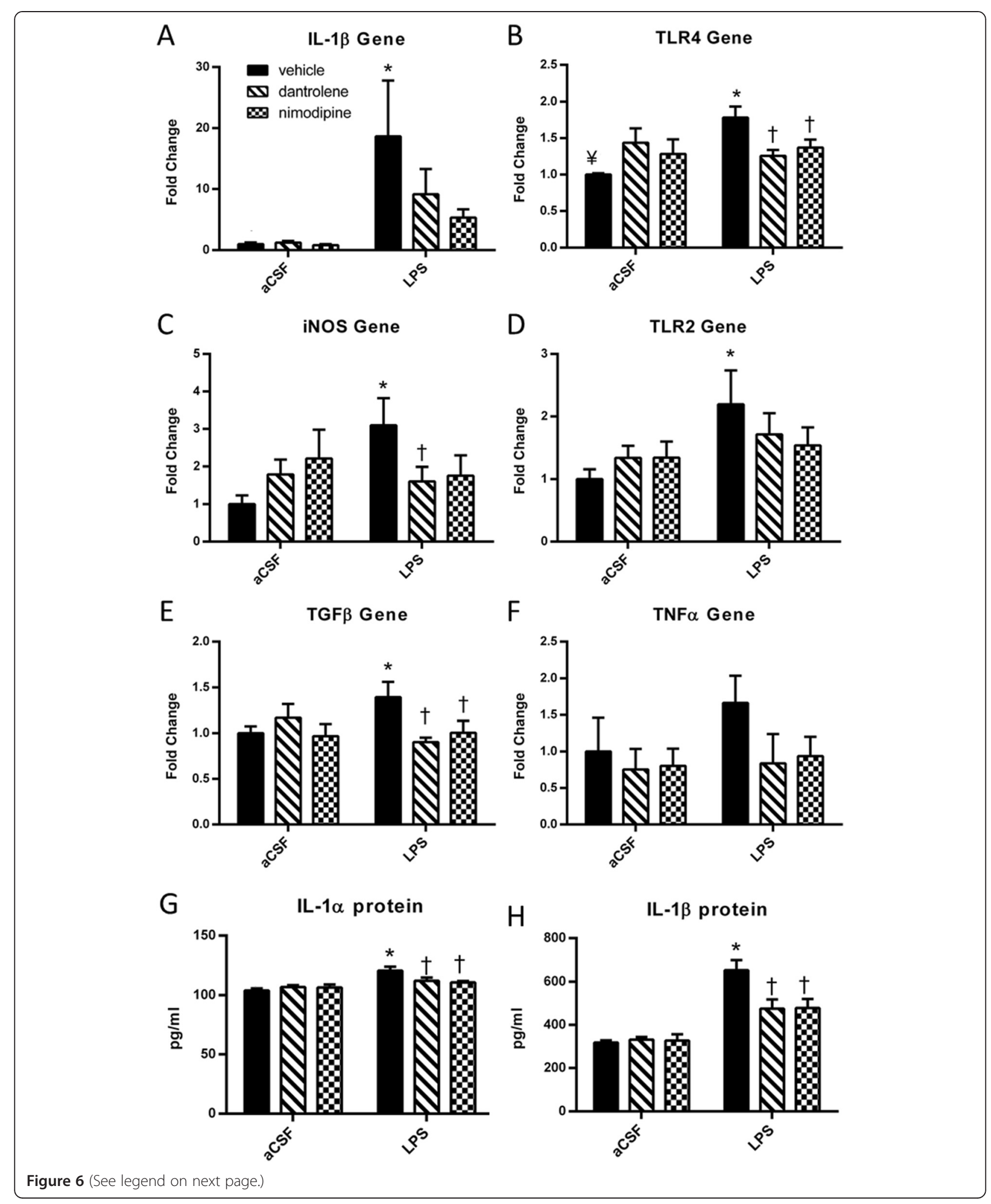


(See figure on previous page.)

Figure 6 Chronic LPS infusion increased gene and protein expression of several inflammatory markers and these increases were reduced by treatment with either dantrolene or nimodipine. Gene expression of IL-1 $\beta$ (A), TLR4 (B), iNOS (C), TLR2 (D), and TGF $\beta$ (E) was significantly increased in LPS + vehicle rats compared to aCSF + vehicle rats. In LPS rats, treatment with nimodipine significantly reduced expression of TLR4 mRNA (B), TGF $\beta$ mRNA (E), IL-1a protein $(G)$, and IL-1 $\beta$ protein $(\mathbf{H})$ and led to a trend in reduction of the IL-1 $\beta$ gene $((A), P=0.053)$ and iNOS gene $((C), P=0.085)$. In LPS rats, treatment with dantrolene significantly reduced the expression of TLR4 gene (B), iNOS gene (C), TGF $\beta$ gene $(E)$, IL-1a protein $(G)$, and IL-1 $\beta$ protein $(H)$. There was no significant change in TNFa gene expression $(\mathbf{F})$. Data expressed as mean \pm SEM. *Indicates a significant difference from treatment-matched aCSF controls, ${ }^{\dagger}$ Indicates a significant difference from LPS + vehicle rats, ${ }^{*}$ Indicates significant difference from aCSF + dantrolene rats. Significance determined by $P<0.05$. LPS lipopolysaccharide, aCSF artificial cerebrospinal fluid, TLR4 Toll-like receptor 4, TLR2 Toll-like receptor 2, iNOS inducible nitric oxide synthase, TGF $\beta$ transforming growth factor $\beta$, TNFa tumor necrosis factor alpha.

(sAHP). Reduction of the sAHP is correlated with improved memory acquisition [37]. This would improve neuronal sensitivity to relevant event-related stimuli, which may be overshadowed by $\mathrm{Ca}^{+2}$ "noise" during neuroinflammation. Indeed, blockade of tumor necrosis factor alpha (TNF $\alpha)$ signaling during aging reduces agerelated increases in the sAHP and improves memory [38], suggesting a relationship between neuroinflammation, memory, and the enhancement of L-VDCCs. Similarly, increased RyR dysregulation also underlies age-associated $\mathrm{Ca}^{+2}$ dysregulation and increases in the sAHP. In young rats, in vitro RyR blockade reduces the sAHP to a lesser extent compared to L-VDCC antagonism [39]. Aged neurons demonstrate prolonged increases in intracellular $\mathrm{Ca}^{+2}$ levels that are RyR-dependent [40]. Oxidative stress present in aged rats increases the sAHP by $50 \%$ and is dependent on RyRs, but not other sources of $\mathrm{Ca}^{+2}$, including inositol triphosphate receptors and L-VDCCs [36]. Additionally, L-VDCCs and RyRs interact with each other: $\mathrm{Ca}^{+2}$ influx via L-VDCCs triggers $\mathrm{Ca}^{+2}$-induced $\mathrm{Ca}^{+2}$ release via RyRs which in turn modulates L-VDCC activity ([41];). Furthermore, a recent study on patients with late onset AD demonstrated a genetic interaction between L-VDCC and RyR mutations and amyloid deposition [11], demonstrating the importance of these two channels in the AD pathology.

In the present study, dantrolene treatment did not improve memory to the same extent as nimodipine. However, dantrolene was still able to normalize many biochemical changes induced by chronic LPS infusion to the same extent as nimodipine. This discrepancy may be accounted for by dantrolene's interaction with NMDAR function: RyR activation is important for the amplification of NMDAR signals $[26,27]$. While reduction of the sAHP by nimodipine and dantrolene may increase relevant NMDAR signaling, dantrolene may also reduce relevant NMDAR signaling, leading to a disruption of memory performance. On the surface, this concept may be in conflict with our previous observation that NMDAR blockade with the noncompetitive antagonist memantine improves memory during chronic neuroinflammation [32], but memantine' s kinetics allow for relevant signals to pass through [42], making its mechanism of neuroprotective and nootropic effects more similar to nimodipine.

\section{Dantrolene and nimodipine normalize LPS-induced increases} in Arc and intracellular $\mathrm{Ca}^{+2}$

During chronic LPS infusion, Arc expression is increased in the hippocampus, which parallels our previous studies [32]. While Arc is required for late-LTP and memory consolidation and Arc deficiency leads to memory deficits [43], under normal circumstances, its expression is sparse and specific [44], similar to electrophysiological changes that take place during learning and memory. Overexpression of $\operatorname{Arc}$ is most likely not beneficial to memory during chronic neuroinflammation. Arc expression leads to endocytosis of AMPA receptors (AMPAR) [45] and a decrease in AMPAR-mediated excitation and induction of long-term depression (LTD; $[46,47]$ ). Normally, the function of this may be to maintain homeostatic synaptic scaling [48] and would be neuroprotective by decreasing glutamatergic postsynaptic activity. However, an extended increase in Arc could cause a protracted decrease in synaptic excitability or LTD that could eventually lead to increased synaptic elimination [49].

Treatment with dantrolene or nimodipine reduced LPSinduced Arc increases. The mechanism by which dantrolene and nimodipine reduce $A r c$ expression may be due to a reduction in LPS-induced increases of intracellular $\mathrm{Ca}^{+2}$. Indeed, $\operatorname{Arc}$ expression is known to be $\mathrm{Ca}^{+2}$-dependent [29]. Several lines of evidence suggest that there is $\mathrm{Ca}^{+2}$ dysregulation during neuroinflammation. For one, neuroinflammation has been shown to reduce glutamate uptake by $[16,18]$ and potentiate glutamate release from $[50,51]$ glial cells. NMDAR blockade by memantine has been shown to reduce Arc expression during chronic neuroinflammation [32], further supporting this concept. Potentiated $\mathrm{Ca}^{+2}$ entry via L-VDCCs and RyRs by cytokines and other pro-inflammatory markers have also been observed $\left([22,23,33]\right.$. By restoring normal intracellular $\mathrm{Ca}^{+2}$ levels, dantrolene and nimodipine may prevent LPS-induced overexpression of Arc. Indeed, LPS-infused rats had significantly increased ${ }^{45} \mathrm{Ca}^{+2}$ uptake. Previously, $\mathrm{Ca}^{+2}$ dysregulation induced by the pro-inflammatory cytokine IL-1 $\beta$ has been observed directly using $\mathrm{Ca}^{+2}$ imaging in vitro [52]. To the best of our knowledge, this is the first study to directly document $\mathrm{Ca}^{+2}$ dysregulation following in vivo chronic neuroinflammation as opposed to in vitro acute neuroinflammation. Strikingly, nimodipine treatment 
in vivo or ex vivo was able to reverse completely LPSinduced increases in ${ }^{45} \mathrm{Ca}^{+2}$ uptake. These data demonstrate that the L-VDCC blockade is sufficient to reverse LPS-induced $\mathrm{Ca}^{+2}$ dysregulation.

\section{Potential mechanisms by which dantrolene and nimodipine reduce neuroinflammation}

Dantrolene and nimodipine dramatically reduce the number of activated microglia in the hippocampus and reduce the expression of various pro-inflammatory cytokines. It is not clear from our data whether the anti-inflammatory effects of dantrolene and nimodipine are due to direct action on the microglia themselves or an indirect effect via normalization of neuronal $\mathrm{Ca}^{+2}$ levels. Neurotoxicity of conditioned media from activated microglia is reduced when drugs blocking L-VDCCs or RyRs are applied to the microglia cultures [12-14]. However, the in vivo anti-inflammatory effects of these drugs are not so clear-cut. Following facial nerve transection, nimodipine treatment improves motor neuron survival without reducing microglia activation [53]. However, after ischemic-reperfusion injury, nimodipine does improve behavioral outcomes while concurrently reducing microglia activation [54]. Similarly, in vivo treatment with dantrolene is neuroprotective and improves behavioral outcomes in various in vivo models of chronic neurodegenerative disorders such as Huntington's [55], $\mathrm{AD}[56,57]$, and spinocerebellar ataxia [58]. Chronic neuroinflammation is a pathological component in all of these disorders [59-61]. However, these studies did not examine microglia activation, making it difficult to determine whether modulation of neuroinflammation played a role in the improvement garnered by nimodipine and dantrolene in these studies.

These drugs may act by directly reducing microglia activation. Intracellular $\mathrm{Ca}^{+2}$ is directly involved in microglia activation. $\mathrm{Ca}^{+2}$ is required for LPS-mediated microglia activation in vitro, with application of a $\mathrm{Ca}^{+2}$ chelator sufficient to prevent activation and production of proinflammatory species [62]. RyRs and L-VDCCs may be involved in mediating $\mathrm{Ca}^{+2}$-associated microglia activation. Microglia express mRNA of the RyR1 and RyR2 subtypes and application of a RyR antagonist prevents LPS-induced neurotoxicity mediated by microglia [14], suggesting a direct role of RyRs in microglia activation. On the other hand, L-VDCC expression on microglia is still debated; the in vitro anti-inflammatory effect of nimodipine may be mediated by off-target effects of nimodipine [12]. Specifically, nimodipine may act by inhibiting the microglia NOX pathway directly, resulting in reduced superoxide production [13]. Earlier studies showed that activation of L-VDCCs increased superoxide production as well as $\mathrm{Ca}^{+2}$ influx in microglia, which could be blocked by nifedipine, a drug closely related to nimodipine [63]. Regardless of whether microglia express functional L-VDCCs, it is possible that nimodipine is exerting direct anti-inflammatory effects during chronic LPS infusion.

L-VDCC blockers, such as dantrolene and nimodipine, can also relax vascular smooth muscle by inhibiting $\mathrm{Ca}^{+2}$ influx leading to vasodilation in the presence of cerebral vasospasms induced by subarachnoid hemorrhage that can lead to brain ischemia, oxidative stress, and neuroinflammation [64]. However, the vascular actions of these drugs most likely do not underlie their beneficial effects in the current study since LPS exposure upregulates the inducible form of nitric oxide synthase leading to an elevated release of nitric oxide [65] and subsequent vasodilation.

Microglia monitor the status of nearby neurons [66] via a variety of channels and receptors. Importantly, microglia can sense depolarization of nearby neurons via $K+$ channels [67]. The data herein show that dantrolene and nimodipine are both capable of reducing LPS-induced increases in hippocampal Arc expression. Because Arc expression requires intracellular $\mathrm{Ca}^{+2}$ [29], it makes sense that these drugs are directly reducing intraneuronal $\mathrm{Ca}^{+2}$ levels, ostensibly reducing neuronal depolarization, which may in turn reduce activation of nearby microglia. Furthermore, neurons suffering from $\mathrm{Ca}^{+2}$ overload are known to alert microglia by release of chemokines [68]. Therefore, reduction of neuronal $\mathrm{Ca}^{+2}$ by nimodipine and dantrolene may prevent activation of microglia by neuronal-mediated mechanisms. Here, we did not observe any effect of LPS or drug treatment on expression of CD200 receptor or ligand (data not shown), indicating that upregulation of CD200 ligand on neurons is not mediating an antiinflammatory feedback mechanism similar to that which is suggested above. Regardless of the specific mechanism, these data suggest that treatment with dantrolene or nimodipine is sufficient to break the self-propagating cycle of neuroinflammation.

\section{Conclusions}

Neuroinflammation drives a self-propagating feed forward cycle, where activated microglia release cytokines and NO that are injurious to neurons, and injured neurons release factors that also activate nearby microglia. Cytokines also feed back onto microglial cytokine receptors, triggering activation of additional nearby microglia. Our model of chronic LPS infusion triggers this cascade: after cessation of LPS infusion, neuroinflammation and memory deficits persist after 5 weeks [29], suggesting that even without LPS present, microglia that have already been activated continue to maintain a pro-inflammatory environment. The ability of dantrolene and nimodipine to disrupt this cycle suggests that $\mathrm{Ca}^{+2}$ dysregulation is a viable target for interrupting the cycle of neuroinflammation that may contribute to neurodegenerative diseases such as AD. 


\section{Competing interests}

The authors declare that they have no competing interests.

\section{Authors' contributions}

SCH, HMD, and RMK performed the surgeries; HMD, AMC, RMK, LA, and SER conducted the behavioral testing and the RT-PCR and protein assays; SCH and GLW conceived and designed the study; SCH performed the statistical analysis; SCH and GLW drafted the manuscript. All authors read and approved the final manuscript.

\section{Acknowledgements}

Supported by U.S. Public Health Service, RO1 AG030331, RO1 AG037320, and The Ohio State University Women and Philanthropy Program to GLW, and Howard Hughes Medical Institute Med-into-Grad fellowship to SCH.

\section{Received: 29 December 2014 Accepted: 9 February 2015} Published online: 25 March 2015

\section{References}

1. Akiyama H, Barger S, Barnum S, Bradt B, Bauer J, Cooper NR, et al. Inflammation and Alzheimer's disease. Neurobiol Aging. 2000;21:383-421.

2. Hanisch U-K, Kettenmann H. Microglia: active sensor and versatile effector cells in the normal and pathologic brain. Nat Neurosci. 2007;10:1387-94.

3. Hauss-Wegrzyniak B, Dobrzanski P, Stoehr JD, Wenk GL. Chronic neuroinflammation in rats reproduces components of the neurobiology of Alzheimer's disease. Brain Res. 1998;780:294-303.

4. Hauss-Wegrzyniak B, Vannucchi MG, Wenk GL. Behavioral and ultrastructural changes induced by chronic neuroinflammation in young rats. Brain Res. 2000:859:157-66.

5. Hauss-Wegrzyniak B, Vraniak PD, Wenk GL. LPS-induced neuroinflammatory effects do not recover with time. NeuroRep. 2000;11:1759-63.

6. Hauss-Wegrzyniak B, Lynch MA, Vraniak PD, Wenk GL. Chronic brain inflammation results in cell loss in the entorhinal cortex and impaired LTP in perforant path-granule cell synapses. Exp Neurol. 2002;176:336-41.

7. Etcheberrigaray R, Hirashima N, Nee L, Prince J, Govoni S, Racchi M, et al. Calcium responses in fibroblasts from asymptomatic members of Alzheimer's disease families. Neurobiol Dis. 1998;5:37-45.

8. Anekonda TS, Quinn JF. Calcium channel blocking as a therapeutic strategy for Alzheimer's disease: the case for isradipine. Biochim Biophys Acta. 1812;2011:1584-90.

9. Tollefson GD. Short-term effects of the calcium channel blocker nimodipine (Bay-e-9736) in the management of primary degenerative dementia. Biol Psychiat. 1990;27:1133-42.

10. Bruno AM, Huang JY, Bennett DA, Marr RA, Hastings ML, Stutzmann GE. Altered ryanodine receptor expression in mild cognitive impairment and Alzheimer's disease. Neurobiol Aging. 2012;33:1001-6.

11. Koran MEl, Hohman TJ, Thornton-Wells TA. Genetic interactions found between calcium channel genes modulate amyloid load measured by positron emission tomography. Human Gen. 2014;133:85-93.

12. Hashioka S, Klegeris A, McGeer PL. Inhibition of human astrocyte and microglia neurotoxicity by $\mathrm{Ca}^{+2}$ channel blockers. Neuropharmacol. 2012;63:685-91.

13. Li Y, Hu X, Liu Y, Bao Y, An L. Nimodipine protects dopaminergic neurons against inflammation-mediated degeneration through inhibition of microglial activation. Neuropharmacol. 2009;56:580-9.

14. Klegeris A, Choi HB, McLarnon JG, McGeer PL. Functional ryanodine receptors are expressed by human microglia and THP-1 cells: their possible involvement in modulation of neurotoxicity. J Neurosci Res. 2007:85:2207-15.

15. McGeer PL, McGeer EG. NSAIDs and Alzheimer disease: epidemiological, animal model and clinical studies. Neurobiol Aging. 2007;28:639-47.

16. Sitcheran R, Gupta P, Fisher PB, Baldwin AS. Positive and negative regulation of EAAT2 by NF-kappaB: a role for N-myc in TNFalpha-controlled repression. EMBO J. 2005;24:510-20.

17. Takaki J, Fujimori K, Miura M, Suzuki T, Sekino Y, Sato K. L-glutamate released from activated microglia downregulates astrocytic L-glutamate transporter expression in neuroinflammation: the "collusion" hypothesis for increased extracellular L-glutamate concentration in neuroinflammation. J Neuroinflam. 2012;9:275-82

18. Prow NA, Irani DN. The inflammatory cytokine, interleukin-1 beta, mediates loss of astroglial glutamate transport and drives excitotoxic motor neuron injury in the spinal cord during acute viral encephalomyelitis. J Neurochem. 2008;105:1276-86.

19. Wu S-Z, Bodles A, Porter M, Griffin WS, Basile A, Barger S. Induction of serine racemase expression and $\mathrm{D}$-serine release from microglia by amyloid betapeptide. J Neuroinflam. 2004;2004(1):2-9.

20. Viviani B, Bartesaghi S, Gardoni F, Vezzani A, Behrens MM, Bartfai T, et al. Interleukin-1 beta enhances NMDA receptor-mediated intracellular $\mathrm{Ca}^{+2}$ increase through activation of the Src family of kinases. J Neurosci. 2003;23:8692-700

21. Orellana DI, Quintanilla RA, Gonzalez-Billault C, Maccioni RB. Role of the JAKs/STATs pathway in the intracellular $\mathrm{Ca}^{+2}$ changes induced by interleukin-6 in hippocampal neurons. Neurotox Res. 2005;8:295-304.

22. Furukawa K, Mattson MP. The transcription factor NF-kappaB mediates increases in $\mathrm{Ca}^{+2}$ currents and decreases in NMDA- and AMPA/kainateinduced currents induced by tumor necrosis factor-alpha in hippocampal neurons. J Neurochem. 1998;70:1876-86.

23. Friedrich $O$, Yi B, Edwards JN, Reischl B, Wirth-Hücking A, Buttgereit $A$. Interleukin-1a reversibly inhibits skeletal muscle ryanodine receptor: a novel mechanism for critical illness myopathy? Am J Respir Cell Mol Biol. 2014:50:1096-106.

24. Palmi M, Meini A. Role of the nitric oxide/cyclic GMP/Ca2+ signaling pathway in the pyrogenic effect of interleukin-1 beta. Molec Neurobiol. 2002;25:133-47.

25. Min SS, Quan HY, Ma J, Han J-S, Jeon BH, Seol GH. Chronic brain inflammation impairs two forms of long-term potentiation in the rat hippocampal CA1 area. Neurosci Lett. 2009:456:20-4.

26. Segal M, Manor D. Confocal microscopic imaging of [Ca2+]i in cultured rat hippocampal neurons following exposure to $\mathrm{N}$-methyl-Daspartate. J Physiol. 1992;448:655-76.

27. Lei SZ, Zhang D, Abele AE, Lipton SA. Blockade of NMDA receptor-mediated mobilization of intracellular Ca2+ prevents neurotoxicity. Brain Res. 1992;598:196-202

28. Foster TC. Dissecting the age-related decline on spatial learning and memory tasks in rodent models: N-methyl-D-aspartate receptors and voltage-dependent Ca2+ channels in senescent synaptic plasticity. Prog Neurobiol. 2012;96:283-303.

29. Waltereit R, Dammermann B, Wulff P, Scafidi J, Staubli U, Kauselmann G, et al. Arg31/Arc mRNA induction by $\mathrm{Ca} 2+$ and CAMP requires protein kinase $A$ and mitogen-activated protein kinase/extracellular regulated kinase activation. J Neurosci. 2001;21:5484-93.

30. Brothers HM, Bardou I, Hopp SC, Kaercher RM, Corona AW, Fenn AM, et al. Riluzole partially rescues age-associated, but not LPS-induced, loss of glutamate transporters and spatial memory. J Neuroimmune Pharmacol. 2013;8:1098-105.

31. Bardou I, Brothers HM, Kaercher RM, Hopp SC, Wenk GL. Differential effects of duration and age on the consequences of neuroinflammation in the hippocampus. Neurobiol Aging. 2013;34:2293-30.

32. Rosi S, Vazdarjanova A, Ramirez-Amaya V, Worley PF, Barnes CA, Wenk GL. Memantine protects against LPS-induced neuroinflammation, restores behaviorally-induced gene expression and spatial learning in the rat. Neurosci. 2006;142:1303-15.

33. Hopp SC, D'Angelo HM, Royer SE, Kaercher RM, Crockett AM, Adzovic L, et al. Spatial memory deficits in aged rats correlate with markers of calcium dysregulation: differential rescue by L-VDCC and RyR antagonism. Neurosci. 2014;240:10-8

34. Thibault O, Landfield PW. Increase in single L-type $\mathrm{Ca}^{+2}$ channels in hippocampal neurons during aging. Science. 1996;272:1017-20.

35. Kumar A, Foster TC. Enhanced long-term potentiation during aging is masked by processes involving intracellular calcium stores. J Neurophysiol. 2004;91:2437-44.

36. Bodhinathan K, Kumar A, Foster TC. Redox sensitive calcium stores underlie enhanced after hyperpolarization of aged neurons: role for ryanodine receptor mediated calcium signaling. J Neurophysiol. 2010;104:2586-93.

37. Disterhoft JF, Thompson LT, Moyer JR, Mogul DJ. Ca ${ }^{+2}$-dependent afterhyperpolarization and learning in young and aging hippocampus. Life Sci. 1996;59:413-20.

38. Sama DM, Mohmmad Abdul H, Furman JL, Artiushin IA, Szymkowski DE, Scheff SW, et al. Inhibition of soluble tumor necrosis factor ameliorates synaptic alterations and Ca2+ dysregulation in aged rats. PLoS One. 2012;7:e38170.

39. Borde M, Bonansco C. Fernández de Sevilla D, Le Ray D, Buño W. Voltage-clamp analysis of the potentiation of the slow Ca2 + -activated K+ current in hippocampal pyramidal neurons. Hippocampus. 2000;10:198-206. 
40. Clodfelter GV, Porter NM, Landfield PW, Thibault O. Sustained Ca2 +- -induced $\mathrm{Ca} 2+-$ release underlies the post-glutamate lethal Ca2+ plateau in older cultured hippocampal neurons. Eur J Pharmacol. 2002;447:189-200.

41. Chavis P, Fagni L, Lansman JB, Bockaert J. Functional coupling between ryanodine receptors and L-type calcium channels in neurons. Nature. 1996:382:719-22

42. Wenk GL, Parsons CG, Danysz W. Potential role of N-methyl-D-aspartate receptors as executors of neurodegeneration resulting from diverse insults: focus on memantine. Behav Pharmacol. 2006;17:411-24.

43. Guzowski JF, Lyford GL, Stevenson GD, Houston FP, McGaugh JL, Worley PF, et al. Inhibition of activity-dependent Arc protein expression in the rat hippocampus impairs the maintenance of long-term potentiation and the consolidation of long-term memory. J Neurosci. 2000;20:3993-4001.

44. Chawla MK, Guzowski JF, Ramirez-Amaya V, Lipa P, Hoffman KL, Marriott LK, et al. Sparse, environmentally selective expression of Arc RNA in the upper blade of the rodent fascia dentata by brief spatial experience. Hippocampus. 2005;15:579-86

45. Chowdhury S, Shepherd JD, Okuno H, Lyford G, Petralia RS, Plath N, et al. Arc/Arg31 interacts with the endocytic machinery to regulate AMPA receptor trafficking. Neuron. 2006;52:445-59.

46. Rial Verde EM, Lee-Osbourne J, Worley PF, Malinow R, Cline HT. Increased expression of the immediate-early gene Arc/arg31 reduces AMPA receptormediated synaptic transmission. Neuron. 2006;52:461-74.

47. Waung MW, Pfeiffer BE, Nosyreva ED, Ronesi JA, Huber KM. Rapid translation of Arc/Arg31 selectively mediates mGluR-dependent LTD through persistent increases in AMPAR endocytosis rate. Neuron. 2008;59:84-97.

48. Shepherd JD, Rumbaugh G, Wu J, Chowdhury S, Plath N, Kuhl D, et al. Arc/Arg31 mediates homeostatic synaptic scaling of AMPA receptors. Neuron. 2006;52:475-84.

49. Wiegert JS, Oertner TG. Long-term depression triggers the selective elimination of weakly integrated synapses. Proc Natl Acad Sci U S A. 2013;110:E4510-9.

50. Takeuchi H, Jin S, Wang J, Zhang G, Kawanokuchi J, Kuno R, et al. Tumor necrosis factor-alpha induces neurotoxicity via glutamate release from hemichannels of activated microglia in an autocrine manner. J Biol Chem. 2006;281:21362-8.

51. Santello M, Bezzi P, Volterra A. TNFa controls glutamatergic gliotransmission in the hippocampal dentate gyrus. Neuron. 2011;69:988-1001.

52. Simões AP, Duarte JA, Agasse F, Canas PM, Tomé AR, Agostinho P, et al. Blockade of adenosine $A(2 A)$ receptors prevents interleukin-1 $\beta$-induced exacerbation of neuronal toxicity through a p38 mitogen-activated protein kinase pathway. J Neuroinflam. 2012;9:204-9.

53. Mattsson P, Aldskogius H, Svensson M. Nimodipine-induced improved survival rate of facial motor neurons following intracranial transection of the facial nerve in the adult rat. J Neurosurg. 1999;90:760-5.

54. Yanpallewar SU, Hota D, Rai S, Kumar M, Acharya SB. Nimodipine attenuates biochemical, behavioral and histopathological alterations induced by acute transient and long-term bilateral common carotid occlusion in rats. Pharmacol Res. 2004;49:143-50.

55. Chen X, Wu J, Lvovskaya S, Herndon E, Supnet C, Bezprozvanny I. Dantrolene is neuroprotective in Huntington's disease transgenic mouse model. Mol Neurodegen. 2011;6:81-9.

56. Oulès B, Del Prete D, Greco B, Zhan X, Lauritzen I, Sevalle J, et al. Ryanodine receptor blockade reduces amyloid- $\beta$ load and memory impairments in Tg2576 mouse model of Alzheimer disease. J Neurosci. 2012;32:11820-34.

57. Peng J, Liang G, Inan S, Wu Z, Joseph DJ, Meng Q, et al. Dantrolene ameliorates cognitive decline and neuropathology in Alzheimer triple transgenic mice. Neurosci Lett. 2012;516:274-9.

58. Chen X, Tang T-S, Tu H, Nelson O, Pook M, Hammer R, et al. Deranged $\mathrm{Ca}^{+2}$ signaling and neurodegeneration in spinocerebellar ataxia type 3. J Neurosci. 2008;28:12713-24.

59. Möller T. Neuroinflammation in Huntington's disease. J Neural Transm. 2010;117:1001-8.

60. Cameron B, Landreth GE. Inflammation, microglia, and Alzheimer's disease. Neurobiol Dis. 2010;37:503-9.

61. Evert BO, Schelhaas J, Fleischer H, De Vos RAl, Brunt ER, Stenzel W, et al. Neuronal intranuclear inclusions, dysregulation of cytokine expression and cell death in spinocerebellar ataxia type 3. Clin Neuropathol. 2006;25:272-81.

62. Hoffmann A, Kann O, Ohlemeyer C, Hanisch U-K, Kettenmann H. Elevation of basal intracellular $\mathrm{Ca}^{+2}$ as a central element in the activation of brain macrophages (microglia): suppression of receptor-evoked $\mathrm{Ca}^{+2}$ signaling and control of release function. J Neurosci. 2003;23:4410-9.
63. Colton CA, Jia M, Li MX, Gilbert DL. K+ modulation of microglial superoxide production: involvement of voltage-gated $\mathrm{Ca} 2+$ channels. Am J Physiol. 1994;266:C1650-5.

64. Salomone S, Soydan G, Moskowitz MA, Sims JR. Inhibition of cerebral vasoconstriction by dantrolene and nimodipine. Neurocrit Care. 2009;10:93-102.

65. Quan N, Sundar SK, Weiss JM. Induction of interleukin-1 in various brain regions after peripheral and central injections of lipopolysaccharide. J Neuroimmunol. 1994;49:125-34.

66. Nimmerjahn A, Kirchhoff F, Helmchen F. Resting microglial cells are highly dynamic surveillants of brain parenchyma in vivo. Science. 2005;308:1314-8.

67. Kettenmann H, Hoppe D, Gottmann K, Banati R, Kreutzberg G. Cultured microglial cells have a distinct pattern of membrane channels different from peritoneal macrophages. J Neurosci Res. 1990;26:278-87.

68. De Jong EK, Dijkstra IM, Hensens M, Brouwer N, Van Amerongen M, Liem $\mathrm{RSB}$, et al. Vesicle-mediated transport and release of CCL21 in endangered neurons: a possible explanation for microglia activation remote from a primary lesion. J Neurosci. 2005;25:7548-57.

\section{Submit your next manuscript to BioMed Central and take full advantage of:}

- Convenient online submission

- Thorough peer review

- No space constraints or color figure charges

- Immediate publication on acceptance

- Inclusion in PubMed, CAS, Scopus and Google Scholar

- Research which is freely available for redistribution 